\title{
An Updated Study of Discovering Blawan-ljen Geothermal Prospect Area Using Gravity and Magnetic Methods
}

\author{
Yunus Daud ${ }^{1,2 *}$, Yasir Arafat ${ }^{1}$, Dhara Adhnandya Kumara ${ }^{2}$, Diah Anastasia Fortuna ${ }^{1}$, Faris Maulana \\ Yunus $^{2}$, Haidar Firdaus Avicienna ${ }^{2}$ and Farhan ${ }^{2}$ \\ ${ }^{1}$ Master Program in Geothermal Exploration, Graduate Program of Physical Science, FMIPA, Universitas Indonesia, \\ Jakarta, Indonesia \\ ${ }^{2}$ Study Program of Geophysics, FMIPA, Universitas Indonesia, Depok, Indonesia
}

\begin{abstract}
The Blawan-Ijen volcanic complex is located in Bondowoso regencies, East Java province. The complex is expected to have geothermal system which is indicated by the occurrence of Blawan hotspring, acid lake on Ijen Crater and alterations. In 2017, measurements of gravity and magnetic methods have been conducted for the first time through the PITTA 2017 program. In 2018, further measurements are carried out to infill the previous data in order to strengthen the interpretation results. There are 151 stations obtained from each method until 2018. In this study, gravity method is used to detect the contrast density of an anomalous body while magnetic method is applied to discover the location of demagnetization zone. This paper presents the integration of both methods in geothermal exploration to determine the geothermal prospect area. The result of CBA and residual gravity indicated the existence of high gravity anomaly in the center to the southwest of the study area. Moreover, after processing RTP on magnetic data, there is the presence of low magnetic anomaly usually associated with demagnetization zone. Generally, the overall results supported one each other and pointed out the occurrence of the geothermal prospect possibly around the center of the study area.
\end{abstract}

Keywords: Blawan-Ijen; geothermal area; gravity; magnetic; prospect zone.

\section{Introduction}

It has been well known that geothermal is renewable and sustainable energy since its source is generated by the earth's core. Geothermal is also a clean energy that does not require carbon-intensive fuel to operate power plant. Therefore, geothermal energy can support Indonesia's target in achieving emission reduction of greenhouse gas (GHG) to 29 percent by 2030 [1].

Indonesia which located along the Pacific Ring of Fire is blessed with huge geothermal potential. One of the area is Blawan-Ijen in East Java. Thus, the occurrence of geothermal system was indicated by the existence of extremely acidic fumarole at Ijen crater and Blawan hotspring.

In 2017, the first magnetic survey was measured in Blawan-Ijen area [2]. Then in 2018, a more comprehensive survey was conducted including further magnetic survey and also gravity survey. The acquisition of both method was done by infilling the stations between the previous measurement to improve the subsurface imaging for understanding the geothermal prospect area in Blawan-Ijen.

Magnetic and gravity methods are commonly used for preliminary survey in geothermal exploration. Magnetic method is an effective method to locate geothermal prospect area characterized with low (negative) magnetic anomaly due to the demagnetization of reservoir rocks. Moreover, gravity method is used to provide information related with density distribution in the subsurface which will be used to identify structures in geothermal prospect area. This paper will present the integrated study between magnetic and gravity methods by combining the data in 2017 and 2018 to discover the geothermal prospect area.

\section{Geological Structure}

Blawan-ijen geothermal area is located inside caldera of Old Ijen Volcano. Nowdays, caldera structure at southern area was deformed into young volcanoes and just leave caldera structure at northern area. Besides, several structures are also detected from remote sensing such as Blawan fault, Pawenan-Blau fault, Djampit fault, Rante fault, Kalipahit-Banyulinu fault, Krepekan fault, 


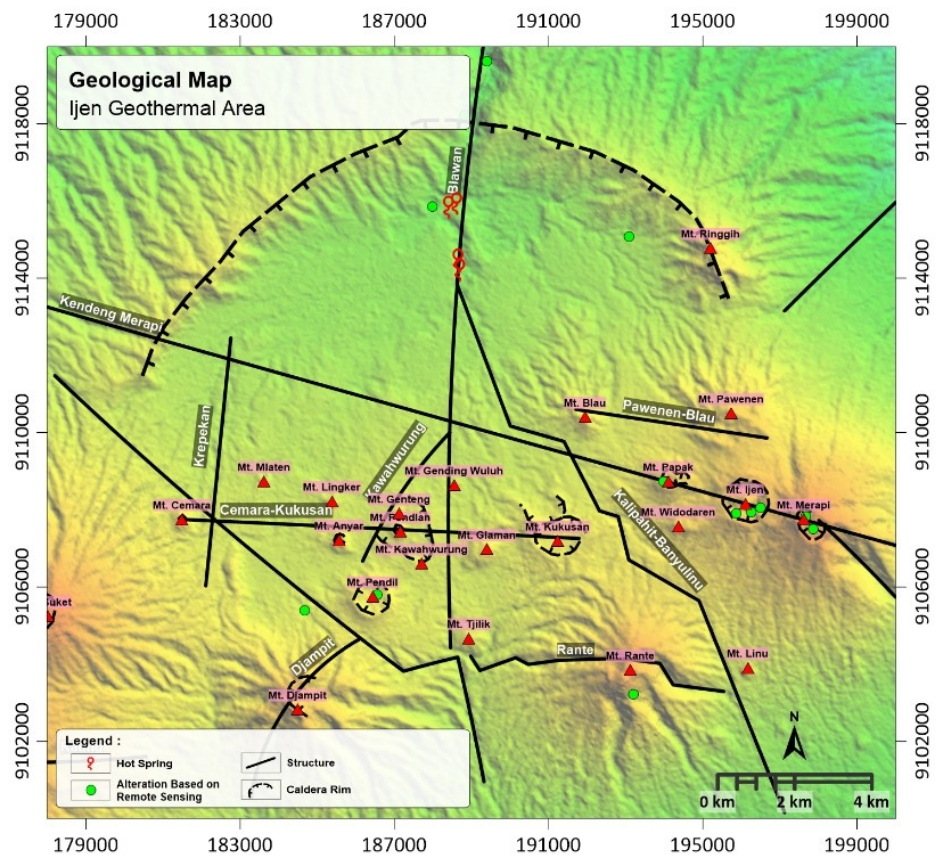

Kawahwurung fault, Kendeng-Merapi fault, and CemaraKukusan fault as shown in Fig 1.

After the acquisition, relative gravity value at each stations were obtained [4]. Relative gravity data were then processed with several corrections such as drift, latitude, free air, bouger and terrain corrections.

\section{Data Acquisition and Processing}

\subsection{Magnetic Method}

Magnetic data acquisition had been acquired at BlawanIjen geothermal prospect area in 2018, following the previous acquisition in 2017. The magnetic data was taken by using Proton Precision Magnetometer (PPM) from GEM System series GSM-19T. Over 151 magnetic stations, where 72 stations acquired in 2017 and 79 stations in 2018 , were distributed with 1 to $1.5 \mathrm{~km}$ grid spacing.

Moreover, several corrections were applied to get magnetic anomalies associated with local magnetic variations of rocks. First, observed magnetic data was corrected for IGRF with the value for this area approximated around $44000 \mathrm{nT}$. Then, it was reduced from

diurnal

Fig. 1. Geological Structure Map of Blawan-Ijen Geothermal Prospect Area

After those correction process, Complete Bouger anomaly (CBA) was obtained. Furthermore, separation of CBA into regional and residual anomalies was done using first order of TSA. Bouguer density was calculated mathematically using the parasnis method with value 2.86 $\mathrm{g} / \mathrm{cm}^{3}$

\section{Results and Interpretations}

\subsection{Gravity Data}

\subsubsection{Complete Bouguer Anomaly}

Fig 2 shows CBA result with a gravity range of value from 40 to $78 \mathrm{mGal}$. A high gravity anomaly can be seen over the center continued variation. Moreover, to separate the dipole effect, Reduction to Pole (RTP) technique was carried out [3]. The magnetic data was reduced with the inclination angle of $-32^{\circ}$. Moreover, upward continuation of 500 meters was performed to reduce the effect of shallow anomaly.

\subsection{Gravity Method}

Jointly with magnetic method, gravity method acquisition was conducted at Blawan-Ijen geothermal prospect area. The design of gravity measurements similar with the magnetic method. The gravity data was carried out by using Scintrex CG-5 Gravimeter. to the southwest area. The high gravity anomaly is probably correlated with the presence of several volcanoes such as Mt. Lengker, Mt. Leker, Mt. Lingker, and Mt. Genteng as a product of intrusion in this area.

Based on the result, the location of geothermal prospect area is estimated possibly around the center and southwest area with high gravity anomaly might be associated with heat source in subsurface. The existence of small caldera structure also supported this interpretation. Meanwhile, the presence of a slightly high gravity anomaly at the northeast area could be related to the caldera wall, due to topography and high density. However, additional data is 


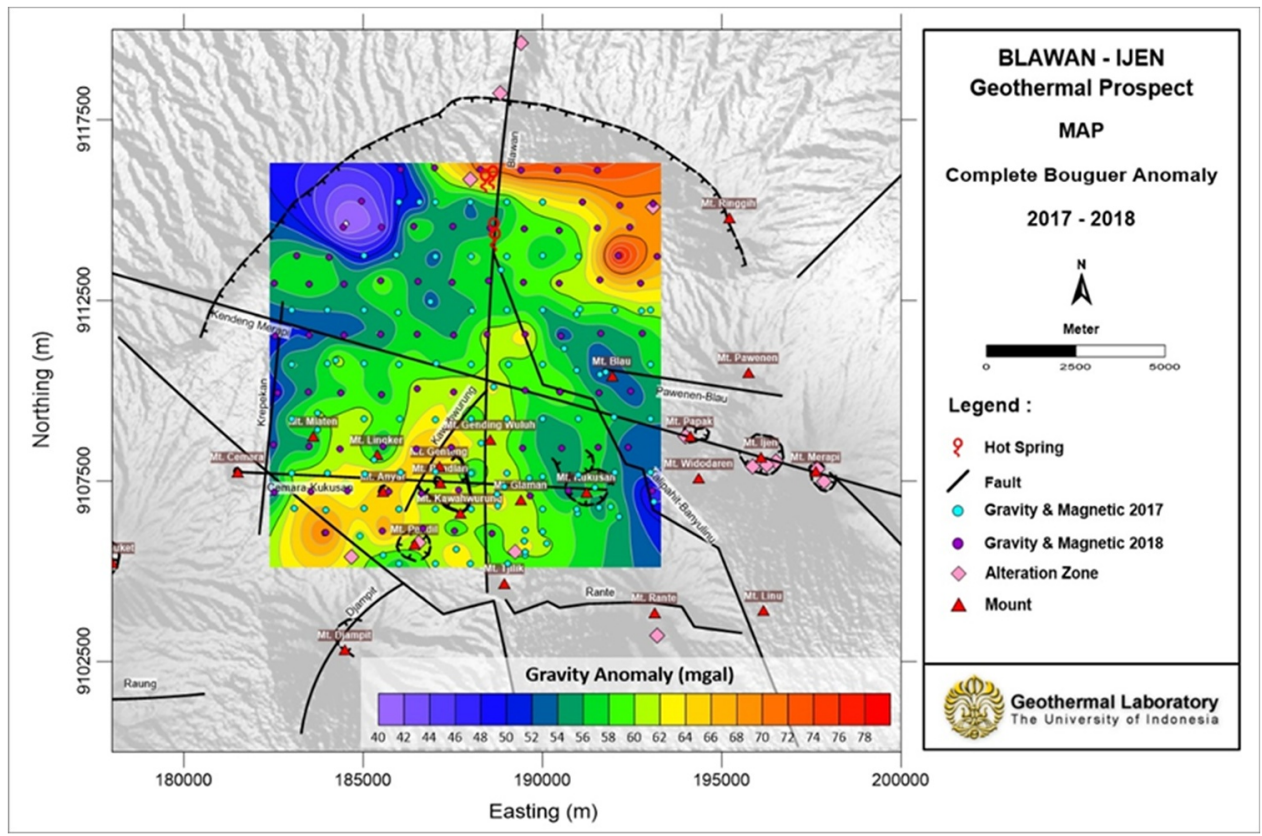

still needed in the northern part area to cover the entire caldera so the result can be more convincing.

\subsubsection{Magnetic Anomaly}

\subsubsection{Residual Anomaly}

Residual anomaly were separated using first order of TSA. The anomaly has a value ranging from -18 to 20

mGal. Generally, the pattern of residual gravity anomaly is similar with the CBA map (Fig 3). It shows that the high gravity anomaly also found at the center to southwest area and northwest area.

\subsection{Magnetic Data}

The result of magnetic anomaly is shown in Fig 4. Its range is between $-1800 \mathrm{nT}$ and $1800 \mathrm{nT}$. The low anomaly mostly covered the eastern side of the study area (blue color) while the positive anomaly is spread at the western

Fig. 3. Residual Anomaly Map

area. The separation between this low-high magnetic pattern is due to the tendency of bipolar anomaly of magnetic data. In the southern part, Several bipolar anomalies which representing the existence of anomolous body in the subsurface are observed. It is probably associated with the occurrence of several volcanoes such as Mt. Lingker and Mt. Cemara-Kukusan.

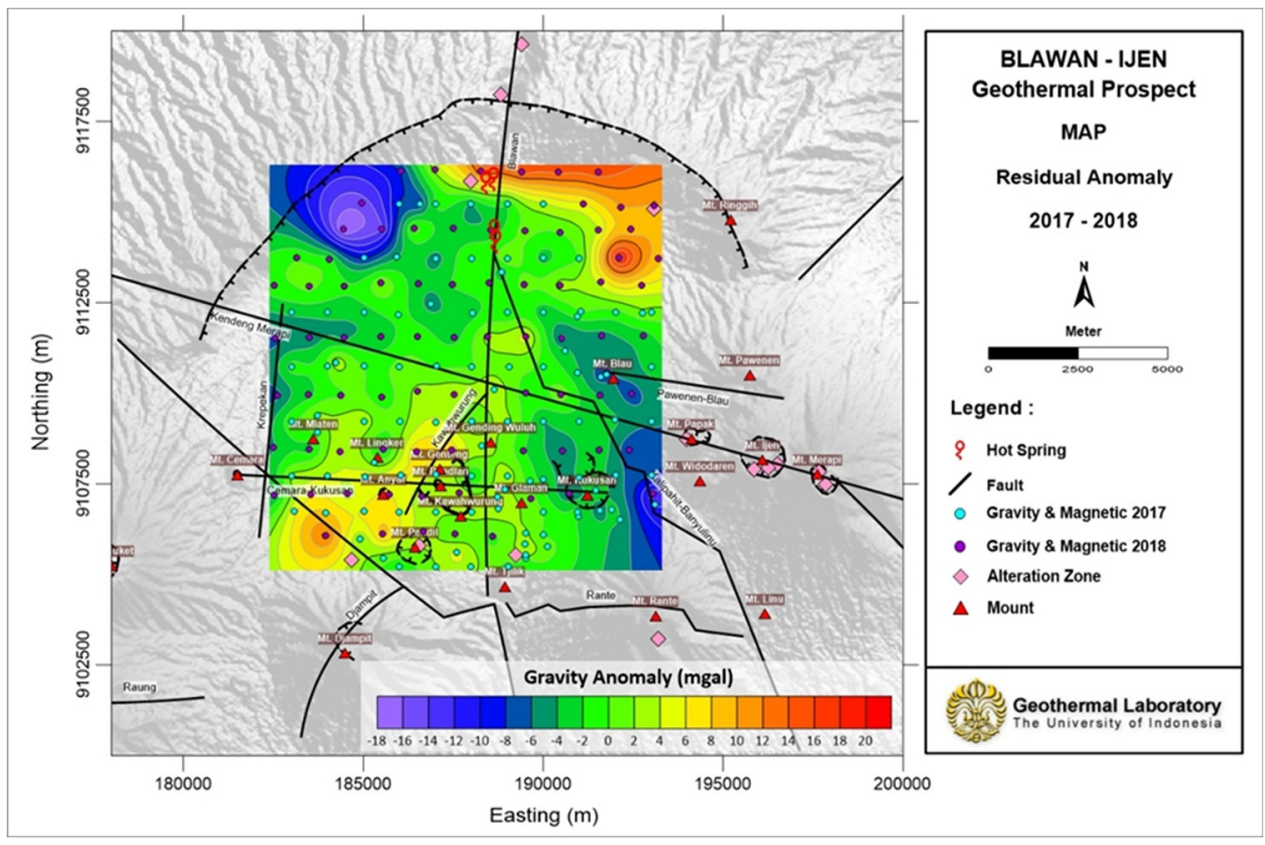




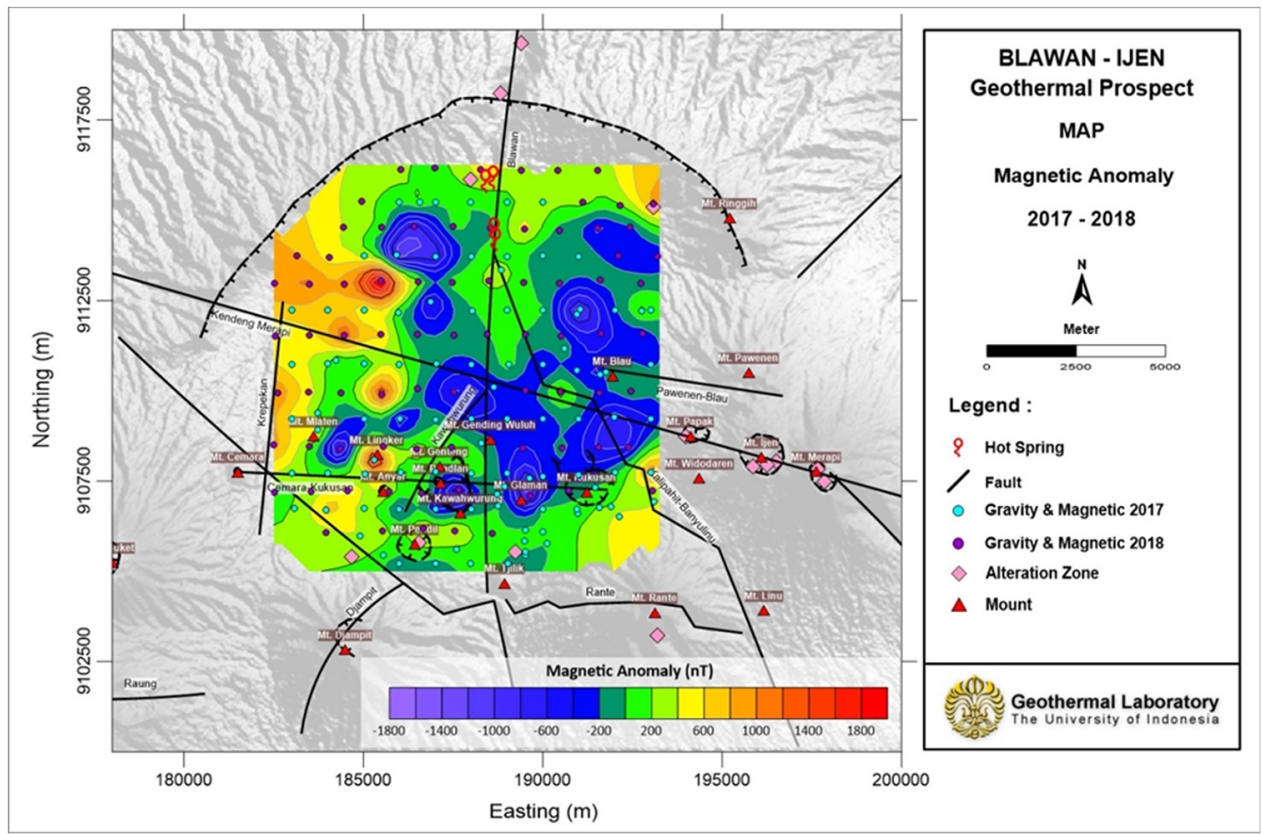

\subsubsection{Reduction to Pole (RTP)}

\subsubsection{Upward Continuation}

Fig. 5. RTP Magnetic Anomaly Map

The RTP map can be seen in Fig 5. RTP anomaly is used to predict the position of geothermal prospect area which is indicated with low (negative) anomaly due to hydrothermal demagnetization [5]. From the result, the pattern of low magnetic anomalies (blue color) is appeared in the northern and continued to center and southern area. It indicates that the prospect zone of Blawan-Ijen probably is located in there. Furthermore, this indication is supported by the existence of several hotsprings at Blawan area as the out-flow zone. The occurrence of those manifestations is probably caused by the permeable pathway from the (predicted to be) up-flow zone due to the intersection of several faults such as
Upward continuation of 500 meters was done to analyze the magnetic anomaly originated from a deep source. The upward continuation was processed using the RTP result as the input. Comparing with the RTP result, generally it has the same pattern of low magnetic anomaly which is represented in blue color. However, after applied by upward continuation, it shows more clearly result of low magnetic anomaly distribution. The low magnetic anomaly in the northern area is increasingly dissapeared and it is mostly concentrated in the center and southern area.

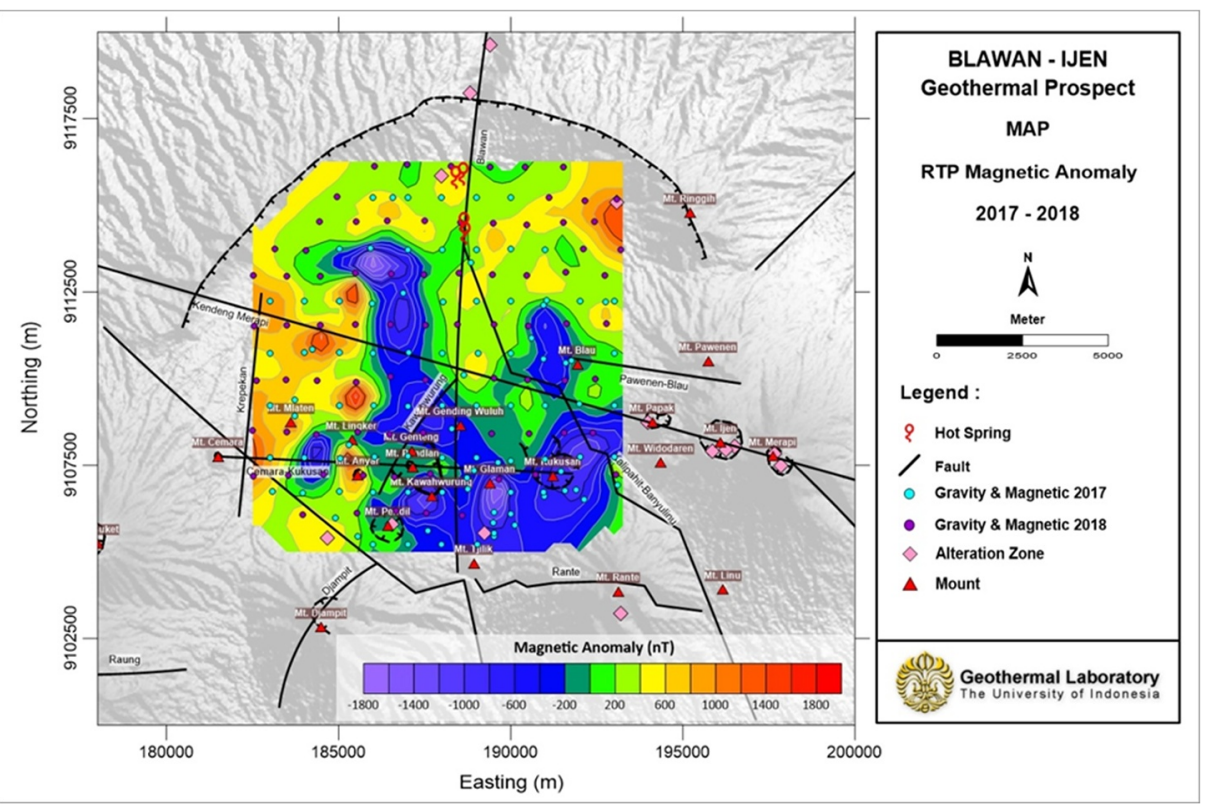

Blawan fault, Cemara-Kukusan fault and Kawahwurung fault. 
From the gravity anomaly map, the high gravity anomaly is observed in the center of study area and continued to southwest. It is estimated to be the heat source of geothermal prospect area which supported by the existence of several volcanoes around.

\section{Acknowledgement}

This work was conducted with funding by DRPM Universitas Indonesia under Hibah PITTA 2018 program, No.2342/UN2.R3.1/HKP.05.00/2018.

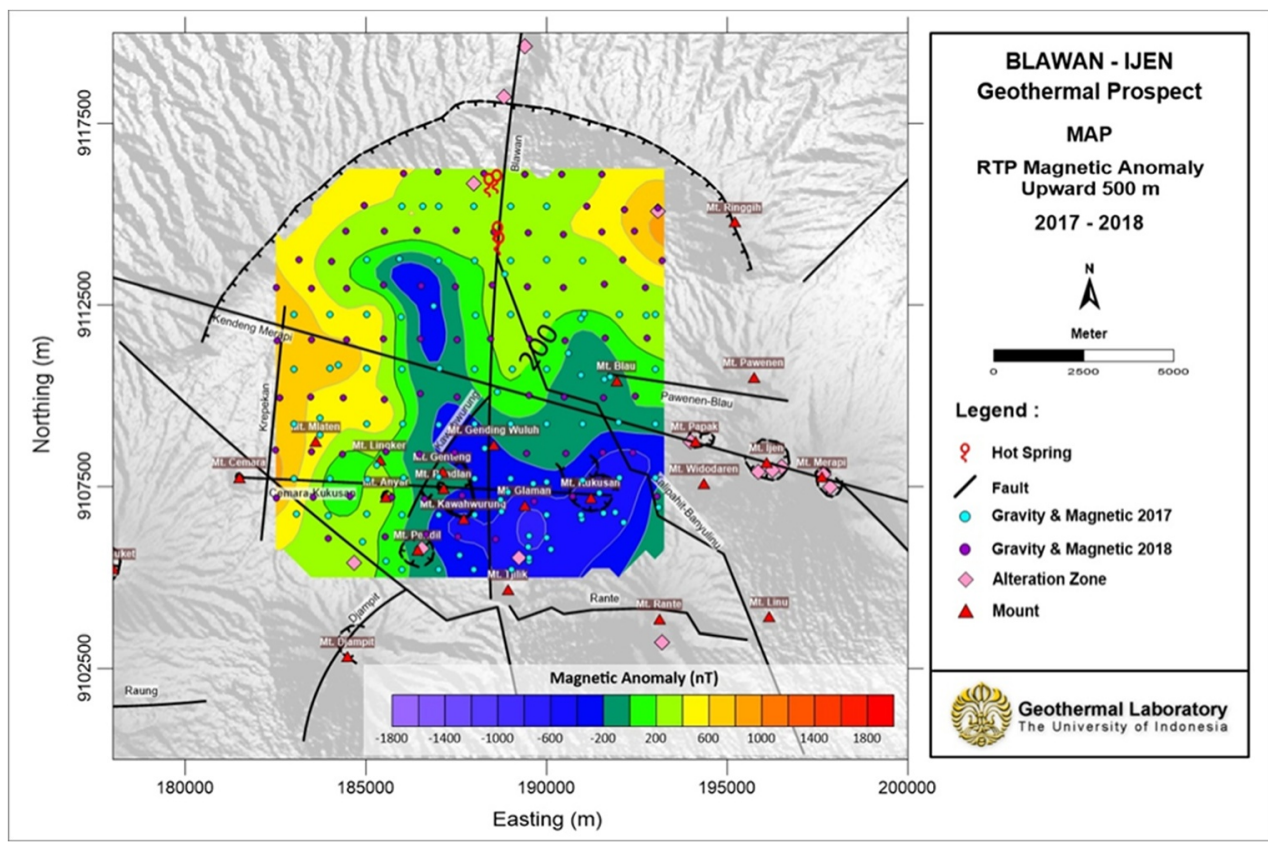

Fig. 6. Upward Continuation of 500 meters Map

Moreover, RTP magnetic anomaly also shows the low magnetic anomaly which indicated the presence of demagnetized hydrothermally rock spread from the northern to the center and southern area. Then, the upward continuation strengthen the prediction of geothermal prospect area which probably located in the center of study area. Based on this results, the presence of manifestations at Blawan can be explained. Probably, the estimation of up-flow zone in the center of study area tend to let the fluid flow towards the northern area, through the permeable zone created by the junction of several faults such as Blawan fault, Kawahwurung fault, and CemaraKukusan fault.

\section{Conclusions}

The result of CBA and residual anomaly 2017 interprets the presence of high gravity anomaly in the northeast area which continues to southwest direction. Meanwhile, after combined with 2018 data, generally it still produced the same pattern but the separation between high gravity anomaly at the center area with northeast area can be seen clearly. Furthermore, the RTP and upward continuation results also show a significant improvement for delineating the geothermal prospect area. It points out that the geothermal prospect area probably located in the center of study area. Furthermore, the result also indicates the continuation of low magnetic anomaly to the southern area.
Support for this work was also provided by PT. Newquest Geotechnology to assist the data processing and also for sharing the knowledge.

\section{References}

1. U. Siagian, B.B. Yuwono, S. Fujimoro and T. Masui. Energies, 10, 52 (2017); doi:10.3390/en10010052.

2. Y. Daud, S. Rosid, F. Fahmi, F.M. Yunus, and R. Muflihendri, Geomagnetic Survey to Explore HighTemperature Geothermal System in Blawan-Ijen, East Java, Indonesia. In E3S Web of Conferences (Vol. 31, p. 02003). EDP Sciences. (2018)

3. D. Ravat, Reduction to pole, Encyclopedia of Geomagnetism and Paleomagnetism, D. Gubbins and E. Herrero-Bervera (eds.), Springer, 856-857. (2007)

4. R. Toushmalani and A. Rahmati, A New Inversion Method of Estimation of Simultaneous Near Surface Bulk Density Variaations and Terrain Corrections Across the Bandar Charak (Hormozgan-Iran). SpringerPlus (Vol. 3(1), p. 135). (2014)

5. S. Soengkono, Airborne Magnetic Surveys to Investigate High Temperature Geothermal Reservoirs. In Advances in Geothermal Energy. InTech. (2016) 